\title{
Current insights into the expression and functions of tumor-derived immunoglobulins
}

\author{
Jing Zhao ${ }^{1,2}$, Hui Peng ${ }^{1,2}$, Jie Gao ${ }^{1}$, Anna Nong ${ }^{1}$, Haoming Hua ${ }^{1}$, Shulin Yang ${ }^{1}$, Liying Chen ${ }^{1}$, Xiangsheng Wu ${ }^{1}$, Hao Zhang ${ }^{1}$ and \\ Juping Wang ${ }^{1 凶}$
}

(c) The Author(s) 2021

Numerous studies have reported expressions of immunoglobulins (Igs) in many human tumor tissues and cells. Tumor-derived lgs have displayed multiple significant functions which are different from classical lgs produced by B lymphocytes and plasma cells. This review will concentrate on major progress in expressions, functions, and mechanisms of tumor-derived Igs, similarities and differences between tumor-derived lgs and B-cell-derived lgs. We also discuss the future research directions of tumor-derived lgs, including their structural characteristics, physicochemical properties, mechanisms for rearrangement and expression regulation, signaling pathways involved, and clinical applications.

Cell Death Discovery (2021)7:148; https://doi.org/10.1038/s41420-021-00550-9

\section{FACTS}

- Classical lgs are produced by B lymphocytes.

- A lot of tumor cells express lgs by themselves.

- Tumor-derived lgs have some specific functions which are different from B-cell-derived lgs, while the mechanisms for the above functions of tumor-derived lgs are unclear.

\section{OPEN QUESTIONS}

- Can any tumor express lgs?

- Which cell signaling pathways are involved in tumor-derived lg-promoted tumor cell growth and proliferation?

- What are the mechanisms by which tumor-derived Igs augment cell migration, invasion, and metastasis?

- What are the mechanisms by which tumor-derived Igs facilitate tumor immune escape?

- Are tumor-derived Igs different from B-cell-derived Igs?

- What are the clinical applications of tumor-derived Igs?

\section{INTRODUCTION}

Ig, a class of globulin with antibody activity, is an important component of disease resistance in the body. It is widely found in blood, tissue fluid, and exocrine fluid, accounting for $\sim 20 \%$ of the total plasma protein [1-4]. Five classes of lgs, namely $\lg A$, $\lg G$, $\lg M$, $\lg \mathrm{E}$, and $\lg \mathrm{D}$, are found in the human body. Each class consists of two identical Ig heavy chains and two identical Ig light chains, which are linked by disulfide bridges to form a "Y"-shaped molecule with twofold symmetry. Ig heavy chains are classified into five major isotypes including $\lg a, \lg \gamma, \lg \mu, \lg \varepsilon$, and $\lg \delta$, and each is specific to its $\lg$ class ( $\lg A, \lg G, \lg M, \lg E$, and $\lg D)$. Among above Ig heavy chains, Igy heavy chains are split into four subtypes including $\lg \gamma 1$, IgY2, Igp3, and $\lg 44$, so $\lg G$ has four subtypes (IgG1, IgG2, IgG3, and IgG4) according to its corresponding heavy chains. Iga heavy chains are similarly split into two subtypes including Iga1 and Iga2, so IgA contains two subtypes ( $\lg A 1$ and $\lg A 2)$ according to its corresponding heavy chains. Ig light chains are classified into two isotypes namely $\lg \lambda$ and $\operatorname{lgk}$, and $\lg \lambda$ is further classified into $\lg \lambda 1, \lg \lambda 2, \lg \lambda 3$, and $\lg \lambda 4$ [5-9]. According to traditional theory, only B lymphocytes and plasma cells can produce and secrete lgs $[10,11]$. However, many research teams recently found that various cancer cells (such as breast cancer, lung cancer, and cervical cancer) can also express lgs, especially lgG [12-15]. At present, more and more studies have shown that tumor-derived lgs play a very important role in the occurrence and development of tumor cells [15-18]. Therefore, further investigation of the roles of tumor-derived lgs in the process of various tumor pathological changes will be helpful to formulate new strategies for the prevention, diagnosis, and treatment of tumors.

\section{Expression of tumor-derived Igs}

Expression of tumor-derived lg heavy chains. The finding of $\mathrm{lg}$ heavy chains in tumor cells dates back to1998. In that year, Kimoto used reverse transcription (RT)- nested PCR to test gene transcripts for the heavy-chain constant regions of $\lg M, \lg D, \lg G 3, \lg G 1, \lg E$, $\lg A$, and $T$-cell receptor- $a$ in five carcinoma cell lines, including SW1116, HEp2, MCF-7, MDA-MB-231, and HC48 [19]. Several years later, other research groups also confirmed the expressions of heavy chains in many tumor tissues and cell lines. A few human Ig heavy-chain constant regions were detected in human

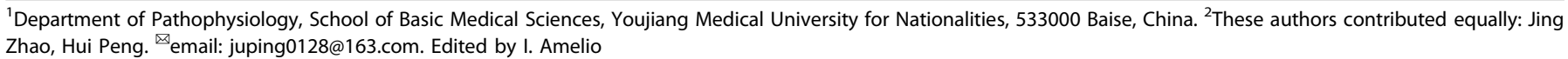

Received: 2 March 2021 Revised: 6 April 2021 Accepted: 13 June 2021

Published online: 28 June 2021 


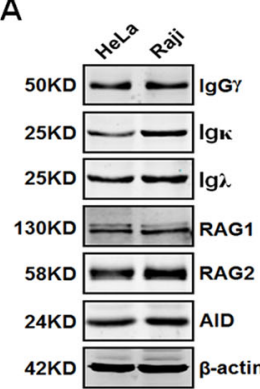

B

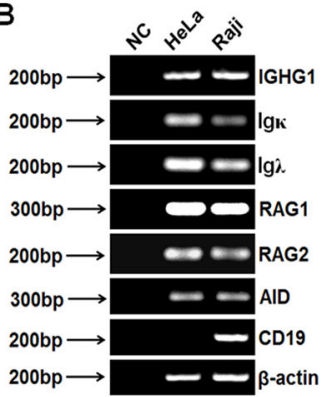

C

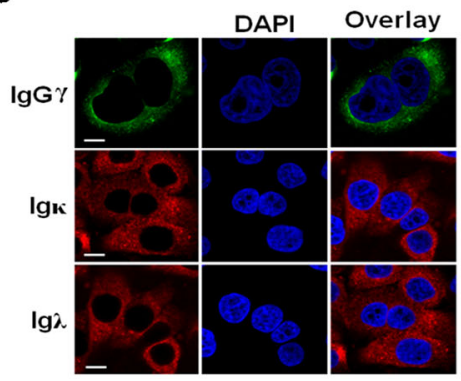

D

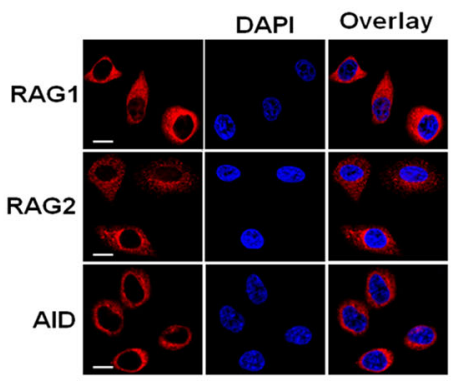

E

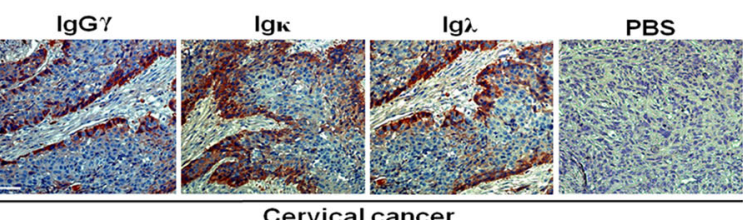

G
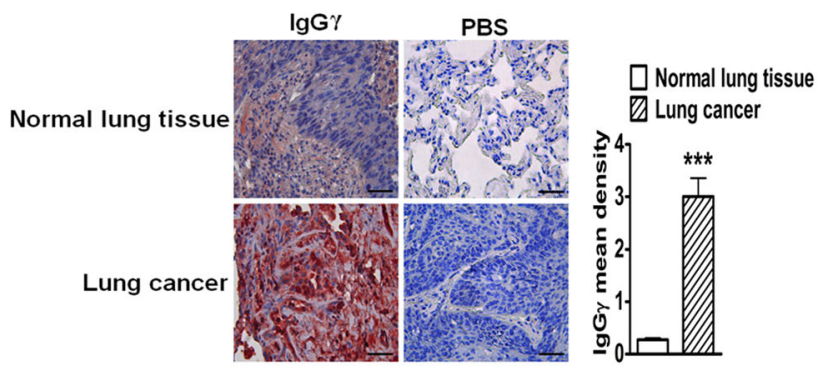

F

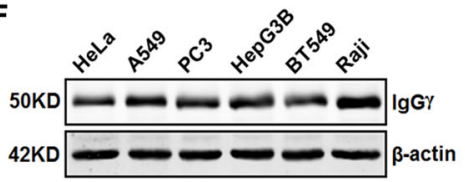

$\mathrm{H}$
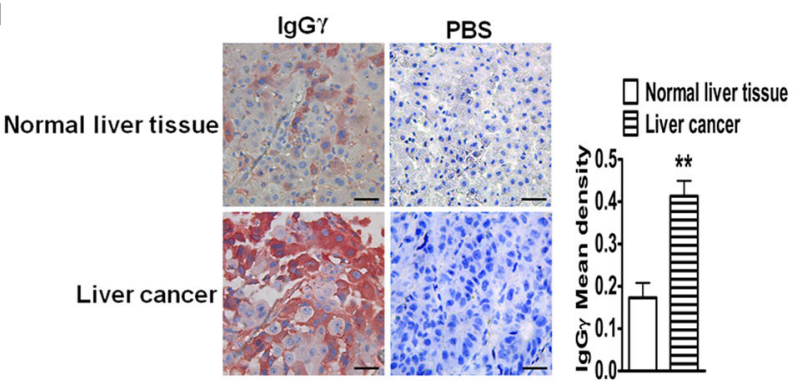

I
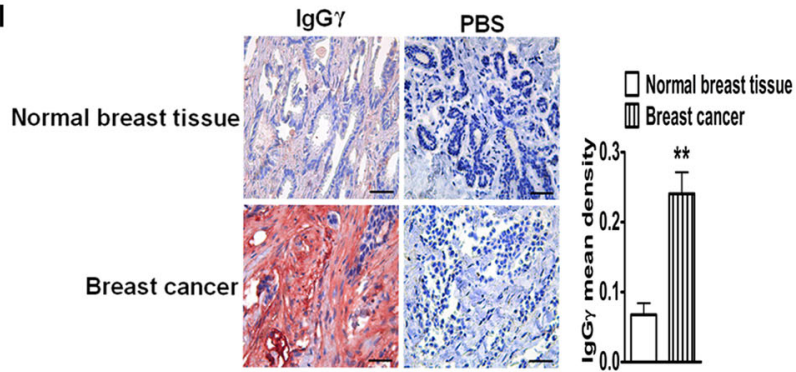

Fig. 1 Expression and distribution of IgG in multiple cancer cells and tissues. A Expressions of IgG Heavy chain $(\gamma)$, light chains $(\lambda$, $\kappa)$, and other related proteins such as RAG1, RAG2, AID were tested with WB in HeLa cells. Raji cells were used as a positive control. $\beta$-actin was used as an internal control. B The above molecule transcripts were measured with RT-PCR. DNase-treated RNA without adding reverse transcriptase was used as a negative control (NC). CD19 was a B lymphocyte marker. C, D Distribution of the above molecules was examined with IF (scale bar, $20 \mu \mathrm{m})$. E Expressions of IgG heavy chain $(\gamma)$, light chains $(\lambda, \kappa)$ in cervical cancer tissues (scale bar, $50 \mu \mathrm{m}$ ). PBS was used as a negative control. F IgG expression at the protein level in HeLa, HEp2, PC3, Hep3B, BT549, and Raji cells. G, H, I The analytic comparison of IgG heavychain $(\gamma)$ expression in normal tissues (lung, liver, breast) and their cancer tissues (scale bar, $20 \mu \mathrm{m}$ ). IgG $\gamma$ mean densities were analyzed in the right panel. PBS was used as a negative control. Reproduced from Wang et al. [15].

hepatocellular carcinomas using CDNA microarray, including lg heavy constant gamma 3 (IGHG3), Ig heavy constant alpha1 (IGHA1), Ig heavy constant mu (IGHM) [20]. Ig heavy-chain V-II region was detected in protein level using two-dimensional electrophoresis in human nasopharyngeal carcinoma cell lines [21]. it was reported that IgA heavy-chain expression was examined using immunohistochemistry (IHC), western blot (WB), and enzyme-linked immunosorbent assay (ELISA) in seven human different cancer cell lines, including MCF-7, SW480, MGC, HeLa, HNE2, CNE1-LMP1, and Tet-on-LMP1-HNE2. The results showed that IgA heavy-chain protein was expressed in the above cancer cells and their supernatants [22]. Zheng et al. found a colorectal cancer-associated gene SNC73 which encoded a peptide identical to the constant region of an $\lg A$ molecule $[23,24]$. They later found expression of SNC73 in gastric cancer, breast cancer, lung cancer, liver cancer, and noncancerous tissues, but the difference of SNC73 expression in the above cancerous tissues and noncancerous tissues was not significant [25]. In addition, they found that the human colon cancer cells (SW480) expressed SNC73, Ig heavy chain a1, recombination activating gene 1 (RAG1), and RAG2 [26]. IgG was reported to express in a number of epithelial malignant tumor cells, such as human breast cancer, colorectal cancer, and liver cancer [16]. In that study, researchers found that lgG was not only localized in the cytoplasm or on the plasma membrane of these cells but also was secreted into cell culture medium [16]. Ig heavy-chain variable region gene expression was examined using nested reverse transcription-PCR in six breast cancer cell lines (BT474, MDA-MB-231, MCF-7, SKBR3, T47D, and ZR75-1) [27]. The above gene transcripts were identifiable in four of six cell lines. IgG heavy chains including variable regions were reported to be expressed in several kinds of carcinoma cell lines, including HT-29, A549, BCL-7402, HeLa S3, and PC3, in both protein and mRNA levels by IHC, in situ hybridization (ISH), and laser microdissection-assisted nested RTPCR $[14,28]$. Zheng et al. demonstrated that human epithelial cancer cells, including HeLa, CNE1, MGC, MCF-7, and SW480, expressed Iga heavy chain. They found that the above cancer cells had the recombination VDJ region and the essential effectors including RAG1 and RAG2, except for activation-induced cytidine deaminase (AID) protein. Moreover, they confirmed that the above cancer cells not only expressed the protein of Iga heavy chain but also secreted the protein into cell culture media [29]. 
Table 1. List of tumor tissues and cell lines expressing Ig heavy chains and/or light chains.

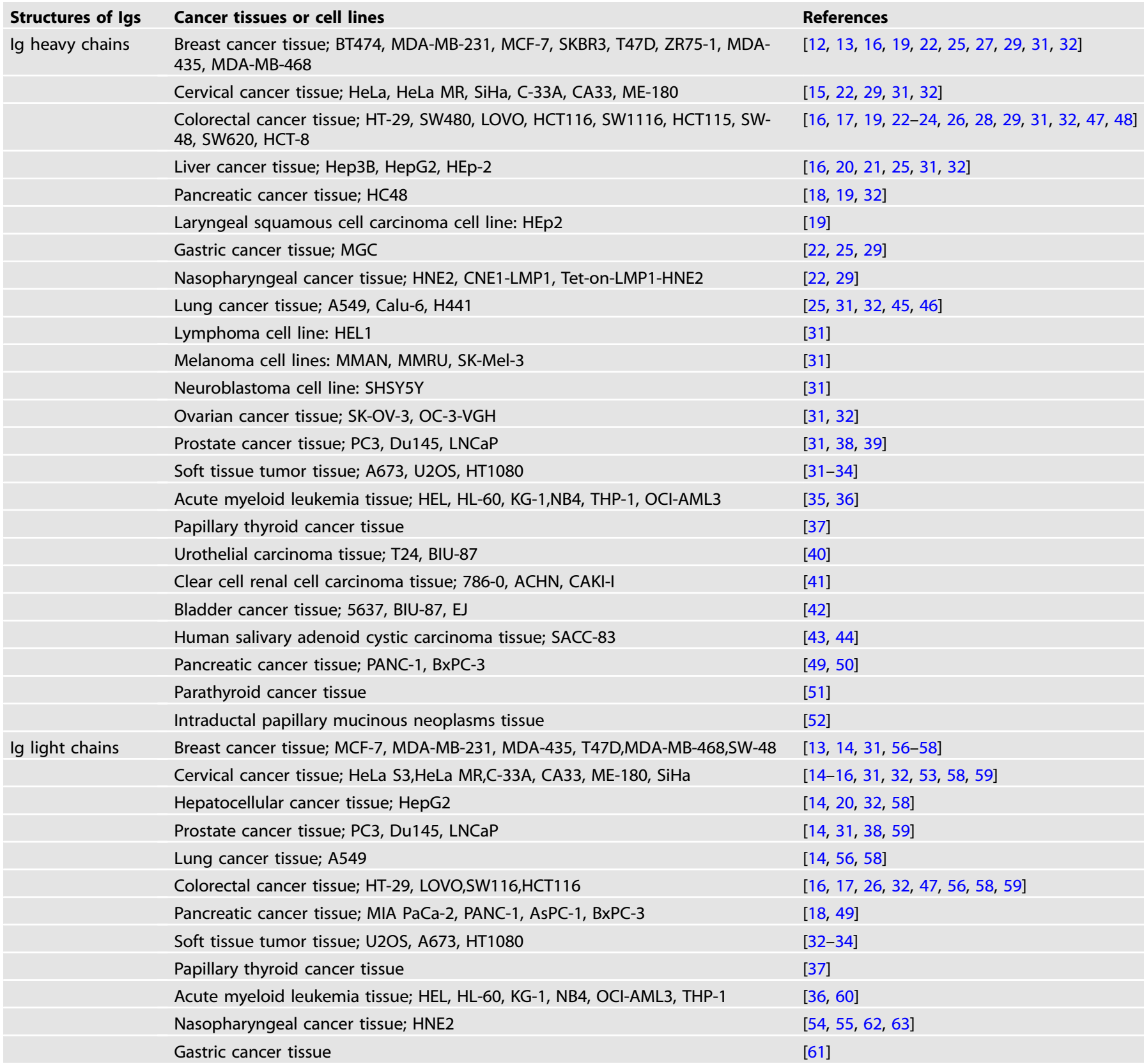

In 2008, lgG and IgA proteins were found in the cytoplasm or plasma membrane or secretion of malignant cells and pleomorphic adenoma tumor cells. In addition, researchers also found rearranged lg gene transcripts in the above tumor cells [30]. Many tumor cells or tissues were confirmed to express Ig heavy chains by WB, nested RTPCR, IHC, or ISH, including breast cancer [12, 13, 31, 32], cervical cancer, colon cancer, liver cancer, lymphoma, melanoma, neuroblastoma, soft tissue lesions [33], soft tissue sarcoma [34], acute myeloid leukemia (AML) [35, 36], ovarian cancer, papillary thyroid cancer [37], prostate cancer $[38,39]$, urothelial carcinoma [40], clear cell renal cell carcinoma (ccRCC) [41], bladder cancer [42], salivary adenoid cystic carcinoma (SACC) $[43,44]$, lung cancer $[45,46]$, colorectal cancer $[17,47]$, colon cancer $[17,48]$, pancreas cancer [18], pancreatic ductal adenocarcinoma $[49,50]$, parathyroid cancer [51], and intraductal papillary mucinous neoplasms [52]. Our previous results demonstrated IGHG1 expression in both protein and mRNA levels in cervical cancer tissues and cell lines, including HeLa and SiHa by RT-PCR, WB, IF, and IHC [15] (Fig. 1).

\section{Expression of tumor-derived Ig light chains}

Many studies have shown that light chains, including $\mathrm{k}$ and $\lambda$, were expressed in a variety of cancer cells. Li et al. analyzed lgk constant region mRNA expression in different stages of cervical tissues using $I S H$. The results showed that the expression of mRNA for the $\mathrm{K}$ constant region in epithelia with dysplasia and carcinoma was higher than that in epithelia with cervicitis. IgK was localized in both the cytoplasm and nuclei of epithelial cells [53]. Igk chain expression was confirmed in nasopharyngeal carcinoma cell line HNE2 by WB, RT$\mathrm{PCR}$, and flow cytometric analysis $[54,55]$. lgk light chain was also reported to be expressed in other tumor cells including breast cancer 
Table 2. List of tumor tissues and cell lines expressing lg-related genes.

\begin{tabular}{|c|c|c|}
\hline Ig-related genes & Cancer tissues or cell lines & References \\
\hline \multirow[t]{11}{*}{ RAG1 } & Breast cancer tissue; MCF-7, BT474 MDA-MB-231, SKBR3, T47D, ZR75-1, Bcap-37 & {$[14,16,18,29,58,66]$} \\
\hline & Colon cancer cell tissue; HT-29, LOVO, SW116, SW480, HCT116 & {$[14,16,17,29,58]$} \\
\hline & Cervical cancer tissue; HeLa S3, HeLa MR & {$[16,29,58]$} \\
\hline & Lung cancer tissue; A549 & {$[16,66]$} \\
\hline & Ovarian cancer tissue; CaOV3, OC-3-VGH & {$[16,31]$} \\
\hline & B lymphocytic leukemia tissue; Raji, Daudi & {$[16,29,66]$} \\
\hline & Nasopharyngeal carcinoma cell line: CNE1 & [29] \\
\hline & Gastric cancer cell line: MGC & [29] \\
\hline & Thyroid cancer tissue & [36] \\
\hline & Prostate cancer tissue; PC3, LNCaP, Du145 & {$[37,66]$} \\
\hline & Ewing's sarcoma cell line: A673 & [33] \\
\hline \multirow{9}{*}{ RAG2 } & Cervical cancer tissue; HeLa S3, HeLa MR & {$[16,29,58]$} \\
\hline & Lung cancer tissue; A549 & {$[16,66]$} \\
\hline & Ovarian cancer tissue; $\mathrm{CaOV} 3, \mathrm{OC}-3-\mathrm{VGH}$ & {$[16,31]$} \\
\hline & B lymphocytic leukemia tissue; Raji, Daudi & {$[16,29,66]$} \\
\hline & Esophagus carcinoma cell line: HEp2 & [14] \\
\hline & Nasopharyngeal carcinoma cell line: CNE1 & [29] \\
\hline & Gastric cancer cell line: MGC & [29] \\
\hline & Thyroid cancer tissue & [36] \\
\hline & Prostate cancer tissue; PC3, LNCaP, Du145 & {$[37,66]$} \\
\hline \multirow{10}{*}{ AID } & Prostate cancer cell line: PC3 & [14] \\
\hline & Burkitt lymphoma cell line: Raji & {$[14,29]$} \\
\hline & Nasopharyngeal carcinoma cell line: CNE1 & [29] \\
\hline & Gastric cancer cell line: MGC & [29] \\
\hline & Colon cancer cell line: SW480 & [29] \\
\hline & Thyroid cancer tissue & [36] \\
\hline & Ovarian cancer cell line: OC-3-VGH & [31] \\
\hline & Ewing's sarcoma cell line: A673 & [33] \\
\hline & Osteosarcoma cell line: U2OS & [33] \\
\hline & Colorectal Cancer tissue; LOVO, HCT116 & [17] \\
\hline \multirow[t]{7}{*}{$\mathrm{I}_{\mathrm{H}}-\mathrm{C}_{\mathrm{H}}$} & Cervical cancer cell line: HeLa & [29] \\
\hline & Nasopharyngeal carcinoma cell line: CNE1 & [29] \\
\hline & Gastric cancer cell line; MGC & [29] \\
\hline & Breast cancer cell lines: MCF-7, BT474, MDA-MB-231, SKBR3, T47D, ZR75-1 & {$[18,29]$} \\
\hline & Colon cancer cell line: SW480 & [29] \\
\hline & Burkitt lymphoma cell line: Raji & [29] \\
\hline & Myeloma cell lines: XG-2, XG-7 & [29] \\
\hline
\end{tabular}


$[13,14,31,56-58]$, colorectal cancer $[16,17,26,32,47,56,58,59]$, lung carcinoma $[14,56,58], \operatorname{AML}[36,60]$, hepatocellular cancer $[14,32,58]$, cervical cancer [14, 16, 31, 32, 53, 58, 59], prostate cancer [14, 31, 38, 59], gastric cancer [61], papillary thyroid cancer [37], soft tissue tumors [32-34], pancreas cancer [18, 49], and nasopharyngeal carcinoma $[62,63]$.

The expression of the $\lg \lambda$ light chain was also examined. Researchers analyzed the expressions of $\lg \lambda$ and $\lg \kappa$ light chains in gastric cancer cells in 22 human gastric cancer tissue specimens by the IHC method-LSAB method. The results demonstrated only $\lg \lambda$ expression in $1(4.5 \%)$ and co-expression of $\lg \lambda$ and $\lg K$ light chains in 17 (77.3\%) among all specimens, suggesting that coexpression of $\lg \lg \lambda$ and $\lg K$ light chains in gastric cancer cells was common [61]. Ig $\lambda$ light chain was also found to be expressed in other tumor cells, including hepatocellular cancer [20], pancreas cancer [18, 49], breast cancer [31], cervical cancer [31, 59], prostate cancer [31, 59], gastric cancer [61], colorectal cancer [59], and AML [36]. The tumor tissues and cell lines that express Ig heavy chains and/or light chains are summarized in Table 1.

\section{Molecular regulatory mechanisms of tumor-derived Ig expression}

B-cell-derived Igs are assembled by $V(D) J$ recombination, which includes randomly choosing a pair of $V, D, J$ gene segments, production of double-strand breaks (DSB) adjacent to each segment, deletion or invertion of the intervening DNA and ligation of the segments together, during lymphocyte development [64]. This recombination is initiated by DSB produced by RAG1 and RAG2 at specific recombination signal sequences [65]. Numerous studies have shown that RAG1 and RAG2 were found to be expressed at both protein and mRNA levels in many cancer cell lines, including colon cancer, lung cancer, cervical cancer, liver cancer, prostate cancer, nasopharyngeal cancer, gastric cancer, breast cancer, papillary thyroid cancer, pancreatic cancer, ovarian cancer, soft tissue sarcoma, and lymphoma [14, 16, 18, 29, 31, 34, 37, 38, 58, 66]. AID, which is required for antibody maturation involving somatic hypermutation, class switch recombination, and lg gene conversion in some species, is also linked to tumorigenesis. It was reported to express in some cancer cells, including papillary thyroid cancer, pancreatic cancer, ovarian cancer, breast cancer, soft tissue sarcoma, cervical cancer, lymphoma, and colorectal cancer using nested RT-PCR [14, 17, 18, $27,31,34,37,67]$. In addition, $\mathrm{I}_{\mathrm{H}^{-}} \mathrm{C}_{\mathrm{H}}$ germ-line switch transcripts (lY$\mathrm{C}_{\gamma}$, la-Ca) were also detected in breast cancer cells (BT474, T47D), soft tissue sarcoma cells (A673, U2OS, and HT1080), pancreatic cancer cells (MIA PaCa-2, PANC-1, AsPC-1, and BxPC-3), cervical cancer cells (HeLa S3), liver cancer cells (Bel-7402), and lymphoma cells (Raji) $[14,18,27,34]$. The tumor tissues and cell lines that express RAG1, RAG2, AID, and $\mathrm{I}_{\mathrm{H}}-\mathrm{C}_{\mathrm{H}}$ germ-line switch transcripts are summarized in Table 2.

The transcription factors play a vital role in the regulation of tumor-derived Ig expression. At present, the transcription factors of the B-cell-derived IgG gene include octamer-related protein 1, 2 (Oct-1, 2), nuclear factor kappa B (NF-kB), B-cell Oct-binding factor1 , etc., while there is no Oct-2 among the transcription factors of tumor-derived lgG. Tumor-derived lgG promoter can be activated, and its two novel positive regulatory elements are located at -800 to $-610 \mathrm{bp}$ and at -610 to $-300 \mathrm{bp}$, respectively [68-72]. Geng et al. explored the expression of a transcript of the Iga1 gene SNC73 and its related genes (RAG1, RAG2, and 3 transcription factors) in cancer cells, including LOVO (colorectal cancer), SW480 (colorectal cancer), HeLa (cervical cancer), SMC7721 (liver cancer), and Bcap-37 (breast cancer). The results showed that SNC73, RAG1, and RAG2 were detected in all of the above cancer cells. The above three transcription factors of RAG1 or RAG2 were EBF, E2A, and Pax5, respectively. EBF was detected at the mRNA level in the above cancer cells, and Pax5 was only expressed in SW480 cells. However, none of the above five tumor cell lines expressed E2A $[58,73]$. Chen et al. reported that three transcription factors of RAG1 (E2A, FOXO1, and FOXP1) were expressed in cancer cells (A549, PC3, MCF-7, and MDA-MB-231) and located in the nuclei of these cells. Upregulated expressions of E2A, FOXO1, or FOXP1 enhanced RAG1 expression, while silencing of E2A, FOXO1, or FOXP1 decreased RAG1 expression in the cancer cells. Histone H3 acetylation and E2A, FOXO1, FOXP1 binding to RAG enhancer (Erag) were confirmed in MCF-7 using chromatin immunoprecipitation. The above results demonstrated that the transcription factors E2A, FOXO1, and FOXP1 regulated RAG1 expression by binding to Erag, which in turn initiated lg gene rearrangement in cancer cells [66]. The above regulatory mechanisms of tumorderived $\mathrm{lg}$ expression are illustrated in Fig. 2A.

The mechanisms of tumor-derived Ig expression mediated by some specific signaling pathways have been reported. Cao et al. found that EBV-encoded latent membrane protein 1 (LMP1) upregulated IgK expression in nasopharyngeal carcinoma (NPC) cells. The inhibitors of JNK and NF-KB (Bay11-7082 and SP600125) attenuated LMP1-enhanced IgK expression in NPC cells,
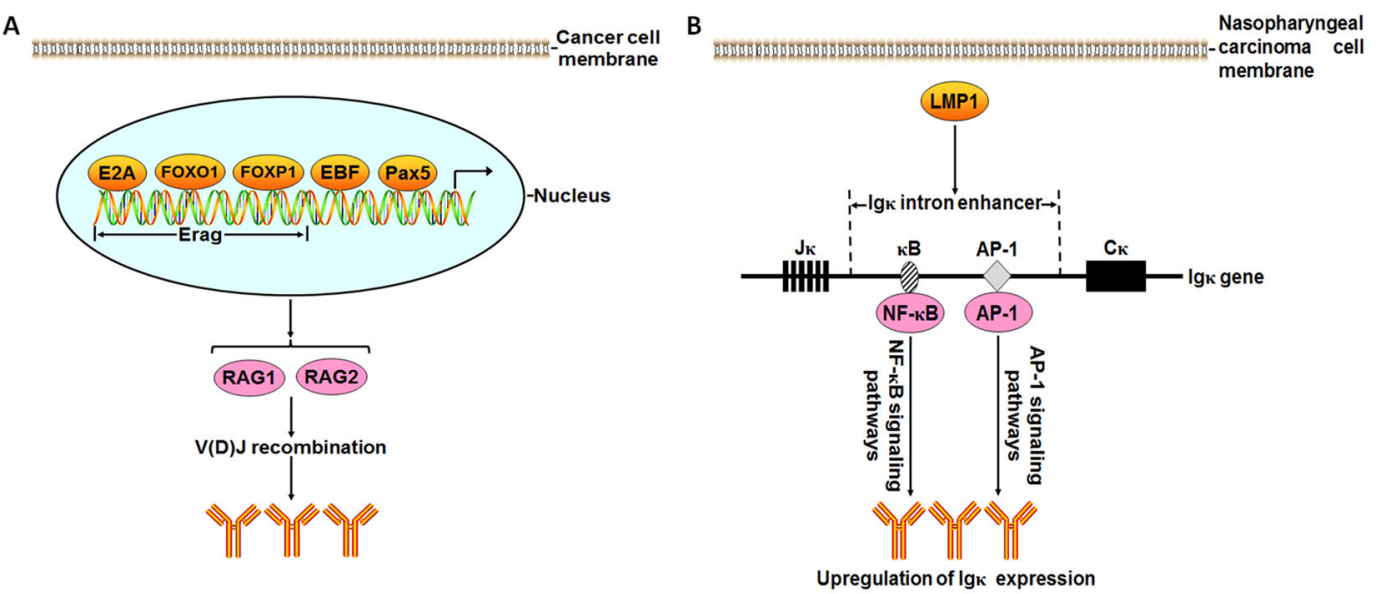

Fig. 2 Schematic illustration of the regulatory mechanisms of tumor-derived Ig expression. A The transcription factors (E2A, FOXO1, FOXP1, EBF, and Pax5) bond to Erag and other RAG promoters to activate transcription of RAG1 and RAG2, which in turn promoted V(D)J recombination of Igs in cancer cells. Finally, tumor-derived Ig expression was upregulated. B LMP1 enhanced lgk intron enhancer activity, which in turn promoted transcription factors NF- $\mathrm{KB}$ (p52 and p65) binding to its corresponding motif as well as AP-1 (c-Jun and c-Fos) binding

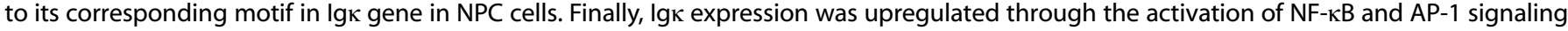
pathways. 
respectively. Compared with their parental cells, LMP1-positive NPC cells, which expressed the dominant-negative mutant of IKBa or c-Jun, displayed markedly low levels of Igk production. These results indicated that LMP1 strengthened lgk expression through NF-KB and activator protein-1 (AP-1) signaling pathways [54]. In addition, Cao et al demonstrated that lgk intron enhancer was active in lgk-expressing NPC cells. LMP1 increased lgk intron enhancer activity, which was involved in NF-KB and AP-1 signaling pathways. LMP1 accelerated transcription factors p52 and p65 binding to the NF-KB motif as well as c-Jun and c-Fos binding to the AP-1 motif in vitro and in vivo. The above results suggested that LMP1 augmented lgk intron enhancer activity, which in turn facilitated the expression upregulation of IgK via NF-KB and AP-1 signaling pathways in NPC cells [55]. The regulatory mechanisms of tumor-derived Igk expression are illustrated in Fig. 2B.

\section{Biological functions and molecular mechanisms of tumor- derived Igs}

According to a multitude of researches, the biological functions of tumor-derived Igs mainly involve four aspects: (1) tumor proliferation; (2) tumor metastasis; (3) tumor immune escape; (4) other functions. The above biological functions of tumor-derived Igs are summarized in Fig. 3.

\section{Promotion of tumor cell growth and proliferation}

In 2003, Qiu et al. found that inhibition of tumor-derived IgG expression by antisense oligodeoxynucleotide and treatment of anti-human IgG antibody induced apoptosis and tumor cell

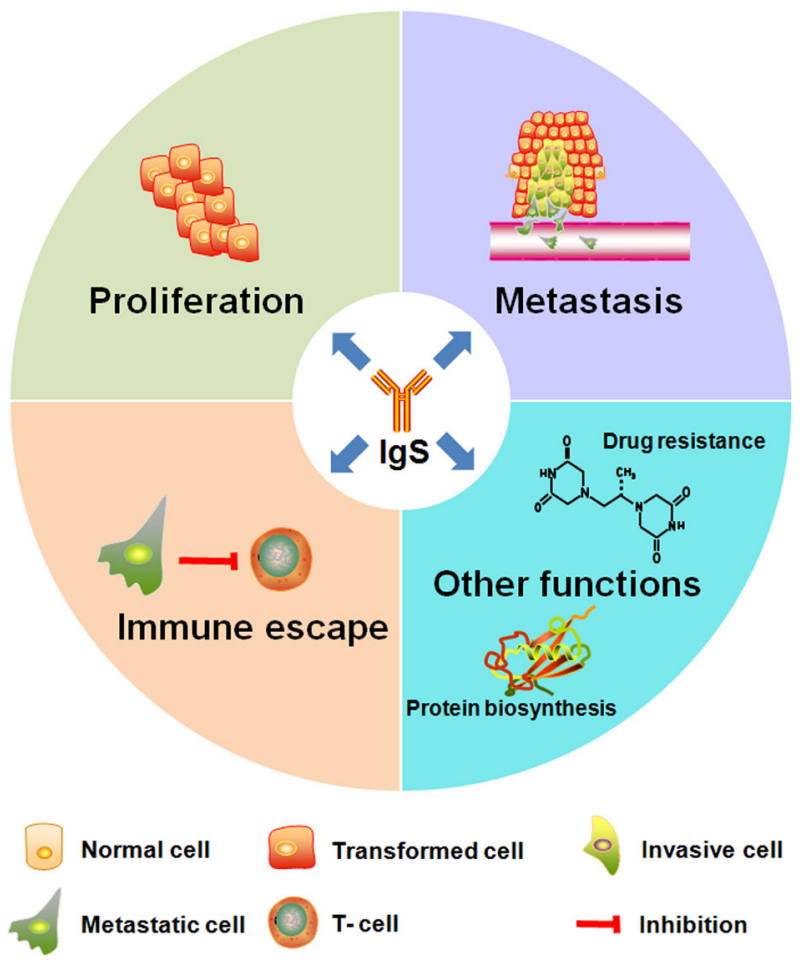

Fig. 3 Schematic illustration of biological functions of tumorderived Igs. Tumor-derived lgs are involved in the following four aspects of tumor development and progression: (1) tumor cell growth and proliferation; (2) tumor cell migration, invasion, and metastasis; (3) tumor immune escape; (4) other biological functions. Other biological functions of tumor-derived lgs are as follows: (1) immunity regulation; (2) promotion of drug resistance; (3) involvement of cancer-associated diabetes; (4) influence of tumor-associated thrombosis; (5) mediation of CSC potential; (6) regulation of cell morphogenesis, cell cycle process, fatty acid biosynthetic process, protein biosynthesis, and antimicrobial (virus, bacterium, and fungus). growth suppression in vitro and in vivo. They concluded that tumor-derived IgG, as a growth factor for epithelial cancers, was a new therapy target of human tumors [16]. Reduction of $\mathrm{Ig}$ expression led to cell growth inhibition and apoptosis in HT-29, suggesting that tumor-derived lg strengthened the survival and growth of colon cancer cells [28]. Blockade of tumor-derived Iga inhibited the growth, viability, and access of $S$ phase of cancer cells including HeLa and CNE1 by anti-human Iga antibody, suggesting that tumor-derived Iga promoted cancer cell growth [74]. Chen et al. analyzed the relation between lgG expression and proliferation markers (proliferating cell nuclear antigen, $\mathrm{Ki}-67$, and cyclin D1) in sarcomas tissues based on double immunostaining of the same tissue slide. The results demonstrated that the labeling index of the above proliferation markers was significantly higher in sarcomas tissues with high lgk expression than that in sarcomas tissues with low lgk expression, suggesting that IgG may be a useful marker for cell proliferation in sarcomas due to the well correlation between lgG and proliferation markers and tumor grades [33]. Blockade of tumor-derived IgG decreased the viabilities of AML cells (HL-60 and OCl-AML3) and prostate cancer cells (PC3 and Du145) and induced apoptosis using anti-human IgG antibody [35, 38]. Treatment with mouse anti-human IgG $\gamma$ antibody or silencing of IgG inhibited cell proliferation and/or induced apoptosis of cancer cells (colorectal cancer cell lines LOVO and SW480, cervical cancer cell line HeLa, gastric cancer cell line MGC, and breast cancer cell line MCF-7), which suggested that IgG promoted the above cancer cell proliferation [17, 47, 75]. In 2013, Liang et al. reported that blockade of tumor-derived IgG by either anti-human lgG antibody or antisense oligonucleotides increased cell apoptosis and upregulated cleaved caspase- 3 and cleaved poly (ADP-ribose) polymerase in bladder cancer cell line $\mathrm{T} 24$ in vitro and in vivo. These findings revealed tumor-derived IgG promoted bladder cancer cell proliferation through inhibiting apoptosis [40].

In the past few years, our research group got some progress on the biological functions of tumor-derived lgG. Our research group gained 27 potential IgG $\gamma$ heavy-chain-interacting proteins by coimmunoprecipitation combined with liquid chromatographytandem mass spectrometry (LC-MS/MS) identification in HeLa cells. We found that at least half of these proteins were closely related to the growth and proliferation of cancer cells. Further studies showed that tumor-derived IgG can strengthen tumor growth and proliferation by inducing the production of low levels of reactive oxygen species [15]. We further found that tumorderived IgG positively regulated LPS-induced proinflammatory cytokine production through binding to toll like receptor4 (TLR4) and increasing its expression. TLR4 has been reported to facilitate the development of many inflammation-induced cancers such as cervical cancer. These findings strongly implied that IgG may enhance cervical cancer cell proliferation via enhancing TLR4 signaling. For above reasons, we concluded that tumorderived IgG may be a new therapeutic target in the treatment of inflammation-mediated cancers [76]. To explore the effects of IgG on gastric cancer proliferation and the roles of ATPases in the above phenomenon, we reduced IgG expression in SGC-7901 and HGC-27 cells using siRNA interference. The result showed that downregulation of IgG inhibited gastric cancer cell proliferation by attenuating the activities of total ATPases and three P-type ATPases. Further studies revealed that reduction of IgG increased levels of nitric oxide (NO) by enhancing the activities of all three isoforms of nitrogen oxide synthase. Meanwhile, sodium nitroferricyanide (III) dihydrate, a NO donor, restained cervical cancer cell proliferation via activating the mitogen-activated protein kinase/p38 (MAPK/p38) signaling pathway, while hemoglobin, a NO scavenger, restored the above biological phenomenon. Taken together, our results indicated that tumor-derived IgG augmented cervical cancer cell proliferation via impairing the production of NO. Other studies demonstrated that tumor-derived IgG, which 
can be recognized by RP215, was mostly located in lamellipodialike structures of the cell surface. Breast cancer cells MDA-MB-231 with IgG high expression showed a greater ability of proliferation, compared with those with IgG low expression [77]. RP215 was found to induce apoptosis of cancer cells in vitro and inhibited the growth of implanted tumors in nude mouse animal models, suggesting that tumor-derived IgG may facilitate cell growth in many cancer cells, including ovary cancer, lung cancer, breast cancer, and chronic myeloid leukemia [78-82]. Downregulation of IgG expression by siRNA or blockade of IgG with anti-human IgG antibody suppressed cell growth and induced apoptosis in many cancer cells, including pancreas cancer cell lines (BXPC-3 and PANC-1) [18] and cCRCC cell lines (786-0 and ACHN) [41]. For these reasons, researchers concluded that tumor-derived IgG may promote cell growth by inhibiting apoptosis in cancer cells. Silencing IGHG1 expression by siRNA attenuated the colony formation, survival, and cell cycle progression in prostate cancer cells (LNCaP, DU145, and PC3). In addition, silencing IGHG1 expression, which decreased PCNA expression, increased caspase3 expression, and inactivated MEK/ERK/c-Myc pathway in the above prostate cancer cells. The above data indicated that tumorderived IGHG1 conferred advantages for the growth and proliferation in prostate cancer cells [83, 84]. Knockdown of tumor-derived lgG by siRNAs inhibited cancer cell proliferation such as SACC cells (SACC-83) [44] and PDAC cells (BxPC-3 and T3M4 cells) [51]. Tumor-derived IgG, which was recognized by RP215, promoted cell proliferation of lung squamous cell carcinoma (LSCC) cell NCl-H520. In addition, RP215 specifically impaired the pro-oncogenic activity of tumor-derived IgG and inhibited in vivo growth of patient-derived xenograft tumors [45]. The mechanisms of action that tumor-derived lgs promote tumor cell growth and proliferation are summarized in Fig. 4.

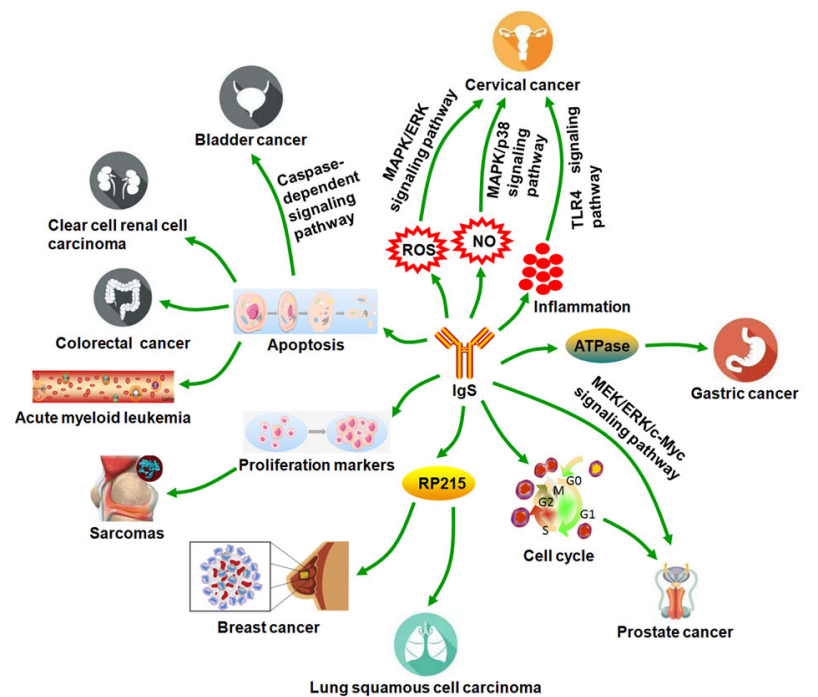

Fig. 4 Schematic illustration of the mechanisms that tumorderived Igs promoted tumor cell growth and proliferation. Tumorderived Igs augmented multiple tumor cell growth and proliferation through positively or negatively regulating the following cell signaling pathways or biological processes or important molecules, including MAPK/ERK signaling pathway, MAPK/p38 signaling pathway, TLR4 signaling pathway, MEK/ERK/c-Myc signaling pathway, caspase-dependent signaling pathway, apoptosis, cell cycle, ATPase, and proliferation markers. Tumor-derived IgG specifically recognized by RP215 promoted cancer (breast cancer and LSCC) cell proliferation.
Enhancement of tumor cell migration, invasion, and metastasis

Multiple reports showed that tumor-derived lgs enhanced various tumor cell migration, invasion, and metastasis. Silencing of lgk reduced cell migration ability in AML cell lines including HL-60 and NB4, whereas Igk overexpression augmented their motility, suggesting that lgk may play an important role in leukemogenesis and serve as a novel therapeutic target or treating AML [60]. Breast cancer cells with IgG high expression had a higher ability of migration, invasion, and metastasis, compared to those with lgG low expression in vitro and in vivo [77]. Ma et al. tested the expressions of lgG in paraffinembedded tissue blocks of 68 breast cancers including 40 primary cancers without metastasis and 28 cancers with axillary lymph node metastases. They found that lgG-expressing breast cancer cells were more evenly distributed in the metastatic cancer cells than that in the primary lesion, suggesting that IgG could be a diagnostic biomarker for breast cancer metastasis [12]. Liu et al. found that the ability of migration and invasion in RP215-positive lung adenocarcinoma cells was higher than that in RP215-negative cells. RP215 immunostaining score was negatively correlated with patient prognosis. Downregulation of IgG impaired lung adenocarcinoma cell migration and invasion. For above reasons, they concluded that RP215 can act as a biomarker for the prognosis of lung adenocarcinoma [85]. Sheng at al. demonstrated that silencing of tumor-derived lgG impaired migration and invasion of bladder cancer cells, such as 5637, BIU-87, and EJ [42]. They later confirmed that the migration and invasion abilities of ccRCC, including 786-0 and ACHN cells, were reduced after IgG expression was knocked down by siRNA. High lgG expression correlated well with the poor differentiation and advanced stage of cCRCC [41]. Lv et al. found that downregulation of tumor-derived lgG decreased cell migration and increased expression levels of $\mathrm{E}$ cadherin and alpha-smooth muscle actin in SACC-83 cells. These results indicated that tumor-derived IgG facilitated SACC cell migration through inducing epithelial-mesenchymal transition (EMT) $[43,44]$.

Other report demonstrated that RP215 recognized tumorderived IgG interacted with integrin a6 $\beta 4$ and augmented the migration and invasion of LSCC cell $\mathrm{NCl}-\mathrm{H} 520$ by activating FAK signaling, while RP215 reversed the above biological phenomenon. These findings indicated that tumor-derived IgG could be an attractive target for antibody-based therapy of LSCC [45]. Debris from necrotic PDAC cells induced IL- $1 \beta$ production by $M 2$ macrophages through the TLR4/TRIF/NF-kB signaling pathway, which was further enhanced by tumor-derived IgG from PDAC cells including PANC- 1 and BxPC-3. In turn, increased IL-1 $\beta$ promoted metastasis of PDAC cells by inducing EMT [49]. Jiang et al. reported that downregulation of IgG expression impeded the migration and invasion ability of colorectal cancer cells SW480. RNA-seq was employed to profile the transcriptomic changes after silencing of tumor-derived IgG in SW480 cells. Bioinformatics analysis showed that 268 differentially expressed genes (DEGs) were identified, including 71 downregulated genes and 197 upregulated genes. These DEGs were mainly apical junction and EMT related to genes. The top-enriched KEGG pathways of these DEGs were cell adhesion, extracellular matrix receptor interaction, and focal adhesion. They further confirmed that tumor-derived IgG facilitated colorectal cancer invasion and metastasis via binding to E-cadherin [47]. Wang et al. found that lgG expression level was positively correlated with clinical stage, $\mathrm{T}$ stage, and metastasis in NSCLC. The gene set enrichment analysis showed that IGHG1 was involved in the following signaling pathways, including cell adhesion, cytokine interaction, and chemokine. On the basis of the above results, they supposed that IgG may act as a poor prognosis factor in NSCLC and participated in cancer invasion and metastasis [46]. Tumor-derived IgG, whose expression was induced by androgen-deprivation therapy and upregulated by SRY (sex-determining region Y)-box 2 (SOX2) in prostate cancer cells such as C4-2 and DU145, promoted the migration and 


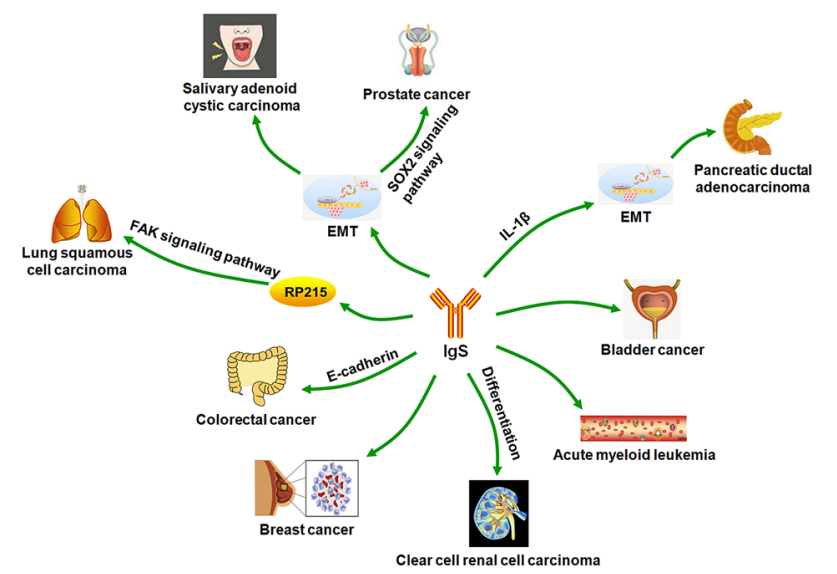

Fig. 5 Schematic illustration of the mechanisms that tumorderived Igs enhanced tumor cell migration, invasion, and metastasis. Tumor-derived lgs augmented multiple tumor cell migration, invasion, and metastasis through positively or negatively regulating the following cell signaling pathways or biological processes or important molecules, including SOX2 signaling pathway, FAK signaling pathway, EMT, differentiation, IL-1 $\beta$, and E-cadherin.

invasion ability of prostate cancer cells through mitogen-activated protein kinase/extracellular signal-regulated kinase and AKT and EMT. The above results suggested that prostate cancer development was promoted through SOX2/tumor-derived IgG signaling pathway [39]. The mechanisms of action that tumor-derived Igs enhance tumor cell migration, invasion, and metastasis are summarized in Fig. 5.

\section{Involvement in tumor immune escape}

There are relatively few reports about lgs involved in the immune escape, compared to those about Igs-mediated tumor cell proliferation and metastasis. Research suggested that IgG and C1q complement was collocated in both primary and metastatic breast cancer lesions, implying that immune complexes may be formed in situ. For the above results, researchers speculated that the above immune complexes may contribute to immune escape of breast cancer cells because tumor-derived IgG, which stops complement-dependent cytotoxicity (CDC) by neutralizing B-cellderived $\mathrm{lgG}$, keeps the host immune system from attacking tumor cells and promotes tumor growth [12] (Fig. 6A). Liu et al. explored the effect of tumor-derived IgG on T-cell activity. They found that tumor-derived lgG, which was purified from ovarian cancer tissue, could suppress the proliferation of $\mathrm{CD}^{+}{ }^{+}$or $\mathrm{CD}^{+} \mathrm{T}$ cells derived from cord blood monocyte cells and cord blood lymphocyte (CBL). In $\mathrm{CBL}, \mathrm{CD}^{+}$or $\mathrm{CD}^{+}{ }^{+}$cells treated with phosphate buffer saline were more active than those treated with tumor-derived IgG or intravenous lg. These findings indicated that tumor-derived IgG had the function of immunomodulation. For the above reasons, they concluded that tumor-derived IgG could promote tumor immune escape by inhibiting T-cell proliferation [86] (Fig. 6B).

A new study demonstrated that tumor-derived lgG, which is recognized by RP215, suppressed effector T-cell proliferation and promoted tumor growth by reducing $\mathrm{CD}^{+}$and $\mathrm{CD}^{+}{ }^{+} \mathrm{T}$-cell infiltration into tumor tissues. Further studies showed that tumorderived IgG directly interacted with sialic acid-binding lg-type lectins (Siglecs), including Siglec-7 and Siglec-10, on effector CD4 ${ }^{+}$ and $\mathrm{CD}^{+} \mathrm{T}$ cells by its sialylation of the $\mathrm{CH} 1$ domain, which finally led to the immunosuppressive effect of T cells and the promotion of tumor growth. Based on these above findings, they supposed that sialylated tumor-derived IgG may be a new ligand for Siglecs which may serve as potential checkpoint molecules and mediate tumor immune escape [87] (Fig. 6C).

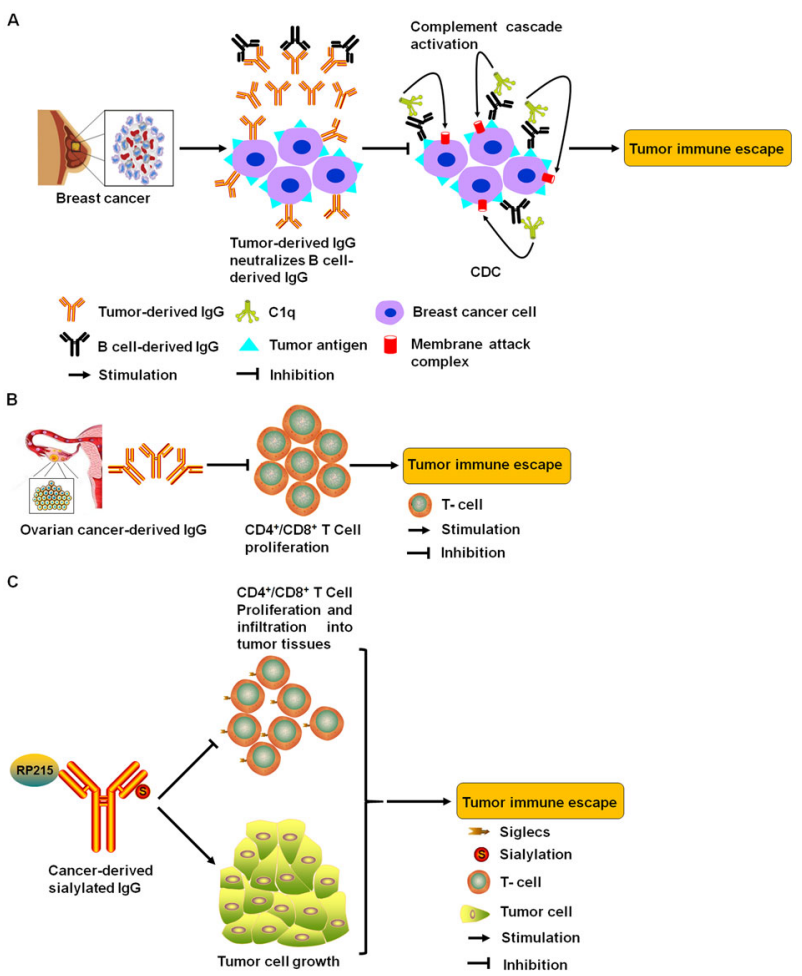

Fig. 6 Schematic illustration of the mechanisms that tumorderived Igs strengthened tumor immune escape. A Tumor-derived lgG neutralized B-cell-derived IgG to block CDC in which the formation of a complex, including B-cell-derived lgG, tumor antigen, and C1q, activated complement cascade to lysis tumor cells with the help of membrane attack complex in breast cancer cells. Finally, breast cancer cells escaped from the host immune system. B Tumorderived lgG inhibited the proliferation of $\mathrm{CD} 4^{+}$or $\mathrm{CD} 8^{+} \mathrm{T}$ cells from CBMC and CBL to facilitate ovarian cancer immune escape. C The sialylation modification mediated the binding between tumorderived IgG, which was recognized by RP215, and Siglecs on effector $\mathrm{CD}^{+}$and $\mathrm{CD}^{+} \mathrm{T}^{+}$cells, which finally resulted in tumor immune escape due to the immunosuppressive effect of the above $T$ cells and the promotion of tumor cell growth.

\section{Other biological functions}

The other biological functions of tumor-derived lgs are as follows: (1) tumor-derived Igs regulate immunity [75]; (2) tumor-derived lgs facilitate drug resistance in tumor cells [77]; (3) tumor-derived lgs might be involved in pancreas cancer-associated diabetes [18]; (4) tumor-derived lgs affect tumor-associated thrombosis [88]; (5) tumor-derived lgs mediate cancer stem cell (CSC) potential [77]. Using co-immunoprecipitation combined with LC-MS/MS, our research group identified six potential tumor-derived IgG whole molecule-interacting proteins, including myosin, heavy chain 9, complement component $4 \mathrm{~A}$, complement component $4 \mathrm{~B}$, acyl$\mathrm{CoA}$ synthetase long-chain family member 3 , ribosomal protein L19 and dermcidin, for obtaining clues to study lgG biological functions. Bioinformatic analysis of the above proteins demonstrated that tumor-derived lgG may be involved in the following biological processes: (1) cell morphogenesis; (2) cell migration; (3) cell cycle process; (4) Ig mediated immune response; (5) fatty acid biosynthetic process; (6) protein biosynthesis; and (7) antimicrobial (virus, bacterium, and fungus) [89].

Similarities and differences between tumor-derived Igs and Bcell-derived Igs

Accumulated evidence demonstrated that there are some similarities and differences between B-cell-derived Igs and tumor-derived lgs. The similarities of the above two types of Igs are as follows: (1) 
Table 3. The similarities and differences between tumor-derived lgs and B-cell-derived lgs.

\begin{tabular}{|c|c|c|c|c|}
\hline & Characteristics & B lymphocyte-derived Igs & Tumor-derived Igs & References \\
\hline \multirow[t]{2}{*}{ Similarities } & Molecular structure & + & + & {$[16]$} \\
\hline & $\begin{array}{l}\text { Natural antibody } \\
\text { activity }\end{array}$ & + & + & [35] \\
\hline \multirow[t]{5}{*}{ Differences } & IgG gene diversity & Unlimited diversity & Limited diversity & [90-93] \\
\hline & Glycosylation patterns & $\begin{array}{l}\text { One N-glycosylation at N297 position and } \\
\text { terminal NeuAc }\end{array}$ & $\begin{array}{l}\text { O-linked and N-linked glycans, } \\
\text { terminal NeuAc and NeuGc }\end{array}$ & [94-98] \\
\hline & $\begin{array}{l}\text { Expression regulatory } \\
\text { mechanisms }\end{array}$ & $\begin{array}{l}\text { Transcription factors include Oct- } 1 \text {, Oct- } 2, N F-\kappa B, B- \\
\text { cell Oct-binding factor-1 and others }\end{array}$ & $\begin{array}{l}\text { Transcription factors include } \\
\text { Oct- } 1 \text { but not Oct- } 2\end{array}$ & {$[72,76]$} \\
\hline & Immunoactivity & Normal & Low & {$[59,99]$} \\
\hline & Biological functions & $\begin{array}{l}\text { Phagocytosis and neutralize toxins (lgG); mucosal } \\
\text { immunity and neonatal immunity (IgA); protection } \\
\text { against invasion of blood by microbial pathogens. } \\
\text { (lgM); initiation of immune responses (lgD). }\end{array}$ & $\begin{array}{l}\text { Tumor proliferation, } \\
\text { metastasis, immune escape, } \\
\text { and other biological behavior } \\
\text { of tumors }\end{array}$ & {$[7-9,15,16,100]$. } \\
\hline
\end{tabular}

molecular structure. Take IgG, for example, they have identical molecular structure, Y-shaped molecule with twofold symmetry [16]; (2) natural antibody activity. Research has proved that tumorderived lgM recognized many self-antigens (HEp2 cell antigens) and non-self-antigens (single-stranded DNA, double-stranded DNA, and lipopolysaccharide). TLR9 agonists (CpG 2006, CpG 2078, and GpC) stimulated HeLa MR cells to secrete IgM through the TLR9-MyD88 signaling pathway. These results demonstrated that cancer-derived IgM contained natural antibody activity like B-cell-derived IgM [32]. Their differences are as follows: (1) lgG gene diversity. B-cell-derived lgG gene contains unlimited diversity, while tumor-derived lgG gene displays limited diversity due to its specific restricted patterns of $\mathrm{V}_{\mathrm{H}} \mathrm{DJ} \mathrm{H}_{\mathrm{H}}$ recombination and distinct somatic hypermutation mechanism of functional $V_{H}$ region gene [90-93]; (2) glycosylation patterns. B-cell-derived IgG has no O-linked glycans, and has only one $\mathrm{N}$ glycosylation at N297 position of IgG heavy chains and terminal Nacetylneuraminic acid (NeuAc), while tumor-derived lgG has not only O-linked and $\mathrm{N}$-linked glycans but also terminal NeuAc and $\mathrm{N}$ glycolylneuraminic acid (NeuGc) [94-98]; (3) expression regulatory mechanisms. The transcription factors of B-cell-derived lgG include Oct-1, 2, and others, while the transcription factors of tumor-derived IgG include Oct-1 but not Oct-2 [72, 76]; (4) immunoactivity or biological activity. The immunoactivity of tumor-derived lgG is significantly lower than that of B-cell-derived IgG [59] because the former has aberrant glycosylations [99]. (5) biological functions. The functions of B-cell-derived lgs include the following: IgG enhances phagocytosis, neutralizes toxins or viruses, and protects fetus or newborn; IgA protects the mucous membranes against microbial pathogens and the newborns against infection during the first month of life; IgM protects against invasion of blood by microbial pathogens; IgD initiates immune responses; IgE plays a vital role in host defenses against certain parasites and hypersensitivity reaction [7-9]. Unlike B-cell-derived Igs, tumor-derived Igs mainly participate in tumor proliferation, metastasis, immune escape, and other biological behaviors of tumors [15, 16, 100]. It should be pointed out that expression levels of tumor-derived lgs in some tumor cells are higher than that of B-cell-derived Igs, while there is an opposite result in other tumor cells according to this study [14, 15]. Furthermore, there are different lg expression levels in different tumor cells [14-16]. The similarities and differences between tumorderived Igs and B-cell-derived Igs are summarized in Table 3.

\section{CONCLUSIONS}

Although outstanding progress has been achieved in the research about tumor-derived lgs in the past decades, more unknown fields of tumor-derived Igs still need to be explored.
Future research can be carried out from the following aspects: (1) structural characteristics of tumor-derived lgs. (2) physicochemical properties of tumor-derived Igs such as biological activities. (3) mechanisms for rearrangement and expression regulation of tumor-derived lgs. (4) exact mechanisms of Igs-mediated cell behaviors, including proliferation, metastasis, immune escape, etc. These mechanisms can be explored from the point of view of related cellular signaling pathways such as MAPK signaling pathways, TLRs signaling pathways, mitochondria-caspase signaling pathway, EMT, etc.

In addition to the above future research fields, the clinical applications of tumor-derived Ig based on the above functions and mechanisms should also be explored. For example, tumorderived IgG can act as a new therapeutic target for many tumors in the future such as salivary adenoid cystic carcinoma [44], colorectal cancer [17, 48], sarcoma [33], and parathyroid cancer [50]. Tumor-derived IgG and IgM might serve as a potential target for AML therapy and useful markers for monitoring minimal residual $A M L[35,101]$. Tumor cell-derived IgG may be a target to prevent and treat tumor-associated thrombosis because it interacted directly with FcyRlla and activated platelets [88]. In addition, monoclonal antibodies targeting tumor-derived lgG as neutralizing antibodies can also be used as antitumor drugs. To our excitement, RP215 monoclonal antibody, which recognized unique carbohydrate-associated epitope(s) in cancer cells, can be applied in immunodiagnostics and developed to antibody-based anticancer drugs [31]. Peptide mimics (R2 and R42) of cancerassociated antigen 215C, which is a carbohydrate-associated epitope of an lg molecule expressed by cancer cells, had been identified to serve as a tumor vaccine candidate [102]. In summary, tumor-derived lgs play a pivotal role in carcinogenesis. More clinical applications of tumor-derived lgs still need to be unveiled in the future.

\section{REFERENCES}

1. Xu Z, Zan H, Pone EJ, Mai T, Casali P. Immunoglobulin class-switch DNA recombination: induction, targeting and beyond. Nat Rev Immunol 2012;12:517-31.

2. Panda S, Ding JL. Natural antibodies bridge innate and adaptive immunity. J Immunol. 2015;194:13-20.

3. Panda S, Zhang J, Tan NS, Ho B, Ding JL. Natural IgG antibodies provide innate protection against ficolin-opsonized bacteria. EMBO J. 2013;32:2905-19.

4. Panda S, Zhang J, Yang L, Anand GS, Ding JL. Molecular interaction between natural lgG and ficolin-mechanistic insights on adaptive-innate immune crosstalk. Sci Rep. 2014;4:3675.

5. Amzel LM, Poljak RJ. Three-dimensional structure of immunoglobulins. Annu Rev Biochem. 1979;48:961-97. 
6. Maibom-Thomsen SL, Trier NH, Holm BE, Hansen KB, Rasmussen MI, Chailyan A, et al. Immunoglobulin $\mathrm{G}$ structure and rheumatoid factor epitopes. PLoS ONE. 2019;14:e0217624.

7. Chi X, Li Y, Qiu X. V(D)J recombination, somatic hypermutation and class switch recombination of immunoglobulins: mechanism and regulation. Immunology. 2020;160:233-47.

8. Schroeder HW Jr, Cavacini L. Structure and function of immunoglobulins. J Allergy Clin Immunol. 2010;125:S41-52.

9. Riesen W. Structure and biological properties of immunoglobulins and gammaglobulin preparations. I. Structure and function of immunoglobulins. Schweiz Med Wochenschr. 1980;110:74-79.

10. Cyster JG, Allen C. B cell responses: cell interaction dynamics and decisions. Cell. 2019;177:524-40.

11. Nutt SL, Hodgkin PD, Tarlinton DM, Corcoran LM. The generation of antibodysecreting plasma cells. Nat Rev Immunol. 2015;15:160-71.

12. Ma C, Wang Y, Zhang G, Chen Z, Qiu Y, Li J, et al. Immunoglobulin G expression and its potential role in primary and metastatic breast cancers. Curr Mol Med. 2013;13:429-37.

13. Yang B, Ma C, Chen Z, Yi W, McNutt MA, Wang Y, et al. Correlation of immunoglobulin $G$ expression and histological subtype and stage in breast cancer. PLOS ONE. 2013;8:e58706.

14. Chen Z, Gu J. Immunoglobulin G expression in carcinomas and cancer cell lines. FASEB J. 2007;21:2931-8.

15. Wang J, Lin $D$, Peng $H$, Huang $Y$, Huang J, Gu J. Cancer-derived immunoglobulin $G$ promotes tumor cell growth and proliferation through inducing production of reactive oxygen species. Cell Death Dis. 2013;4:e945.

16. Qiu X, Zhu X, Zhang L, Mao Y, Zhang J, Hao P, et al. Human epithelial cancers secrete immunoglobulin $\mathrm{G}$ with unidentified specificity to promote growth and survival of tumor cells. Cancer Res. 2003;63:6488-95.

17. Niu N, Zhang J, Huang T, Sun Y, Chen Z, Yi W, et al. IgG expression in human colorectal cancer and its relationship to cancer cell behaviors. PLoS ONE. 2012;7: e47362.

18. Wan X, Lei Y, Li Z, Wang J, Chen Z, McNutt M, et al. Pancreatic expression of immunoglobulin $G$ in human pancreatic cancer and associated diabetes. Pancreas. 2015;44:1304-13.

19. Kimoto Y. Expression of heavy-chain constant region of immunoglobulin and Tcell receptor gene transcripts in human non-hematopoietic tumor cell lines. Genes Chromosomes Cancer. 1998;22:83-86.

20. Okabe H, Satoh S, Kato T, Kitahara O, Yanagawa R, Yamaoka Y, et al. Genomewide analysis of gene expression in human hepatocellular carcinomas using cDNA microarray: identification of genes involved in viral carcinogenesis and tumor progression. Cancer Res. 2001;61:2129-37.

21. Li J, Tan C, Xiang Q, Zhang X, Ma J, Wang JR, et al. Proteomic detection of changes in protein synthesis induced by NGX6 transfected in human nasopharyngeal carcinoma cells. J. Protein Chem. 2001;20:265-71.

22. Li M, Tang M, Deng X. Positive immunoglobulin A expression in human epithelial carcinoma cell lines. Zhonghua Zhong Liu Za Zhi. 2001;23:451-3.

23. Zheng S, Cao J, Geng L. Structure and expression of colorectal cancer related Immunoglobulin novel gene SNC73. Zhonghua Yi Xue Za Zhi. 2001;81:485-8.

24. Hu J, Deng Y, Zheng S. Expression of a novel immunoglobulin gene SNC73 in human cancer and its significance. Zhonghua Zhong Liu Za Zhi. 2002;24:38-40.

25. Hu JB, Zheng S, Deng YC. Expression of a novel immunoglobulin gene SNC73 in human cancer and non-cancerous tissues. World J Gastroenterol. 2003;9:1054-7.

26. Geng LY, Zheng S, Peng JP. Expression and recombination mechanism of SNC73 (IgHalpha1) in human epithelial cancer cell line. Zhonghua Yi Xue Za Zhi. 2003;83:1493-6.

27. Babbage G, Ottensmeier CH, Blaydes J, Stevenson FK, Sahota SS. Immunoglobulin heavy chain locus events and expression of activation-induced cytidine deaminase in epithelial breast cancer cell lines. Cancer Res. 2006;66:3996-4000.

28. Deng YQ, Zheng J, Li GH, Zhu XH, Zhang P, Huang J, et al. Immunoglobulin expression in colon cancer cell line HT-29 and its biological activities. Zhonghua Zhong Liu Za Zhi. 2006;28:88-91.

29. Zheng H, Li M, Ren W, Zeng L, Liu HD, Hu D, et al. Expression and secretion of immunoglobulin alpha heavy chain with diverse VDJ recombinations by human epithelial cancer cells. Mol Immunol. 2007;44:2221-7.

30. Zhu X, Li C, Sun X, Mao Y, Li G, Liu X, et al. Immunoglobulin mRNA and protein expression in human oral epithelial tumor cells. Appl Immunohistochem Mol Morphol. 2008;16:232-8.

31. Lee G, Ge B. Cancer cell expressions of immunoglobulin heavy chains with unique carbohydrate-associated biomarker. Cancer Biomark. 2009;5:177-88.

32. Hu F, Zhang L, Zheng J, Zhao L, Huang J, Shao W, et al. Spontaneous production of immunoglobulin $M$ in human epithelial cancer cells. PLoS ONE. 2012;7: e51423.
33. Chen Z, Huang X, Ye J, Pan P, Cao Q, Yang B, et al. Immunoglobulin G is present in a wide variety of soft tissue tumors and correlates well with proliferation markers and tumor grades. Cancer. 2010;116:1953-63.

34. Chen Z, Li J, Xiao Y, Zhang J, Zhao Y, Liu Y, et al. Immunoglobulin G locus events in soft tissue sarcoma cell lines. PLoS ONE. 2011;6:e21276.

35. Qiu X, Sun X, He Z, Huang J, Hu F, Chen L, et al. Immunoglobulin gamma heavy chain gene with somatic hypermutation is frequently expressed in acute myeloid leukemia. Leukemia. 2013;27:92-99.

36. Wu L, Xia M, Sun X, Han X, Zu Y, Jabbour EJ, et al. High levels of immunoglobulin expression predict shorter overall survival in patients with acute myeloid leukemia. Eur J Haematol. 2020;105:449-59.

37. Qiu Y, Korteweg C, Chen Z, Li J, Luo J, Huang G, et al. Immunoglobulin G expression and its colocalization with complement proteins in papillary thyroid cancer. Mod Pathol. 2012;25:36-45.

38. Liu Y, Chen Z, Niu N, Chang Q, Deng R, Korteweg C, et al. IgG gene expression and its possible significance in prostate cancers. Prostate. 2012;72:690-701.

39. Qin C, Sheng Z, Huang X, Tang J, Liu Y, Xu T, et al. Cancer-driven IgG promotes the development of prostate cancer though the SOX2-ClgG pathway. Prostate. 2020;80:1134-44.

40. Liang PY, Li HY, Zhou ZY, Jin YX, Wang SX, Peng $X H$, et al. Overexpression of immunoglobulin $\mathrm{G}$ prompts cell proliferation and inhibits cell apoptosis in human urothelial carcinoma. Tumour Biol. 2013;34:1783-91.

41. Sheng Z, Liu Y, Qin C, Liu Z, Yuan Y, Hu F, et al. IgG is involved in the migration and invasion of clear cell renal cell carcinoma. J Clin Pathol. 2016;69:497-504.

42. Sheng Z, Liu Y, Qin C, Liu Z, Yuan Y, Yin H, et al. Involvement of cancer-derived lgG in the proliferation, migration and invasion of bladder cancer cells. Oncol Lett. 2016;12:5113-21.

43. Lv WQ, Peng J, Wang HC, Chen DP, Yang Y, Zhao Y, et al. Expression of cancer cell-derived IgG and extra domain A-containing fibronectin in salivary adenoid cystic carcinoma. Arch Oral Biol. 2017;81:15-20.

44. Peng J, Wang HC, Liu $Y$, Jiang JH, Lv WQ, Yang $Y$, et al. Involvement of non-B cell-derived immunoglobulin $\mathrm{G}$ in the metastasis and prognosis of salivary adenoid cystic carcinoma. Oncol Lett. 2017;14:4491-8.

45. Tang J, Zhang J, Liu Y, Liao Q, Huang J, Geng Z, et al. Lung squamous cell carcinoma cells express non-canonically glycosylated IgG that activates integrinFAK signaling. Cancer Lett. 2018;430:148-59.

46. Wang G, Yang X, Zhu G. Expression and clinical significance of cancer-derived immunoglobulin $\mathrm{G}$ in non-small cell lung cancer by bioinformatics and immunohistochemistry. Zhongguo Fei Ai Za Zhi. 2019;22:341-8.

47. Jiang $H$, Kang $B$, Huang $X$, Yan $Y$, Wang $S$, Ye $Y$, et al. Cancer IgG, a potential prognostic marker, promotes colorectal cancer progression. Chin J Cancer Res. 2019;31:499-510.

48. Geng ZH, Ye CX, Huang Y, Jiang HP, Ye YJ, Wang S, et al. Human colorectal cancer cells frequently express IgG and display unique lg repertoire. World J Gastrointest Oncol. 2019;11:195-207.

49. Chen Q, Wang J, Zhang Q, Zhang J, Lou Y, Yang J, et al. Tumour cell-derived debris and IgG synergistically promote metastasis of pancreatic cancer by inducing inflammation via tumour-associated macrophages. $\mathrm{Br} J$ Cancer. 2019;121:786-95.

50. Cui M, You L, Zheng B, Huang X, Liu Q, Huang J, et al. High expression of cancerderived glycosylated immunoglobulin $\mathrm{G}$ predicts poor prognosis in pancreatic ductal adenocarcinoma. J Cancer. 2020;11:2213-21.

51. Cui $M, H u ~ Y$, Zheng B, Zhang $S$, Zhang $X$, Wang $M$, et al. Cancer-derived immunoglobulin G: a novel marker for differential diagnosis and relapse prediction in parathyroid carcinoma. Clin Endocrinol. 2020;92:461-7.

52. Cui M, Liao Q, Li J, Habib JR, Kinny-Köster B, Dong Y, et al. Expression of cancerderived Immunoglobulin $\mathrm{G}$ during malignant progression in intraductal papillary mucinous neoplasms: a pilot study. Pancreas. 2020;49:e51-e54.

53. Li M, Feng DY, Ren W, Zheng L, Zheng H, Tang M, et al. Expression of immunoglobulin kappa light chain constant region in abnormal human cervical epithelial cells. Int J Biochem Cell Biol. 2004;36:2250-7.

54. Liu HD, Zheng H, Li M, Hu DS, Tang M, Cao Y. Upregulated expression of kappa light chain by Epstein-Barr virus encoded latent membrane protein 1 in nasopharyngeal carcinoma cells via NF-kappaB and AP-1 pathways. Cell Signal. 2007;19:419-27.

55. Liu H, Zheng H, Duan Z, Hu D, Li M, Liu S, et al. LMP1-augmented kappa intron enhancer activity contributes to upregulation expression of lg kappa light chain via NF-kappaB and AP-1 pathways in nasopharyngeal carcinoma cells. Mol Cancer. 2009;8:92.

56. Schmidt M, Hellwig B, Hammad S, Othman A, Lohr M, Chen Z, et al. A comprehensive analysis of human gene expression profiles identifies stromal immunoglobulin $\mathrm{K} C$ as a compatible prognostic marker in human solid tumors. Clin Cancer Res. 2012;18:2695-703. 
57. Pandey JP, Kistner-Griffin E, Black L, Namboodiri AM, Iwasaki M, Kasuga Y, et al. IGKC and FcyR genotypes and humoral immunity to HER2 in breast cancer. Immunobiology. 2014;219:113-7.

58. Geng LY, Shi ZZ, Dong Q, Cai XH, Zhang YM, Cao W, et al. Expression of SNC73, a transcript of the immunoglobulin alpha-1 gene, in human epithelial carcinomas. World J Gastroenterol. 2007;13:2305-11.

59. Lee G, Cheung AP, Li B, Ge B, Chow PM. Molecular and immuno-characteristics of immunoglobulin-like glycoproteins in cancer cell-expressed biomarker, CA215. Immunol Investig. 2012;41:429-46.

60. Wang C, Xia M, Sun X, He Z, Hu F, Chen L, et al. IGK with conserved IGKV/IGKJ repertoire is expressed in acute myeloid leukemia and promotes leukemic cell migration. Oncotarget. 2015;6:39062-72.

61. Yang $S$, Wang $M$, You W. Co-expression of immunoglobulin light chain kappa and lambda in gastric carcinoma cell. Zhonghua Zhong Liu Za Zhi. 2002;24:465-6.

62. Li M, Ren W, Weng XX, Liao W, Xia LQ, Deng X, et al. Nucleotide sequence analysis of a transforming gene isolated from nasopharyngeal carcinoma cell line CNE2: an aberrant human immunoglobulin kappa light chain which lacks variable region. DNA Seq. 2001;12:331-5.

63. Cao Y, Sun Y, Poirier S, Winterstein D, Hegamyer G, Seed J, et al. Isolation and partial characterization of a transformation-associated sequence from human nasopharyngeal carcinoma. Mol Carcinog. 1991;4:297-307.

64. Schatz DG, Swanson PC. V(D)J recombination: mechanisms of initiation. Annu Rev Genet. 2011;45:167-202.

65. Chi X, Li Y, Qiu X. V(D)J recombination, somatic hypermutation and class switch recombination of immunoglobulins: mechanism and regulation. Immunology. 2020;160:233-47.

66. Chen Z, Xiao Y, Zhang J, Li J, Liu Y, Zhao Y, et al. Transcription factors E2A, FOXO1 and FOXP1 regulate recombination activating gene expression in cancer cells. PLoS ONE. 2011;6:e20475.

67. Zheng J, Huang J, Mao Y, Liu S, Sun X, Zhu X, et al. Immunoglobulin gene transcripts have distinct VHDJH recombination characteristics in human epithelial cancer cells. J Biol Chem. 2009;284:13610-9.

68. Calame KL. Immunoglobulin gene transcription, molecular mechanisms. Trends Genet. 1989;5:395-9.

69. Lefranc G, Lefranc MP. Regulation of the immunoglobulin gene transcription. Biochimie. 1990;72:7-17.

70. Schubart K, Massa S, Schubart D, Corcoran LM, Rolink AG, Matthias P. B cell development and immunoglobulin gene transcription in the absence of Oct-2 and OBF-1. Nat Immunol. 2001;2:69-74.

71. Pankratova EV, Sytina EV, Luchina NN, Krivega IV. The regulation of the Oct-1 gene transcription is mediated by two promoters. Immunol Lett. 2003;88:15-20.

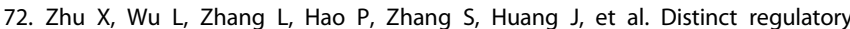
mechanism of immunoglobulin gene transcription in epithelial cancer cells. Cell Mol Immunol. 2010;7:279-86.

73. Romanow WJ, Langerak AW, Goebel P, Wolvers-Tettero IL, van Dongen J, Feeney $A J$, et al. E2A and EBF act in synergy with the $V(D) J$ recombinase to generate a diverse immunoglobulin repertoire in nonlymphoid cells. Mol Cell. 2000;5:343-53.

74. Zheng H, Li M, Liu H, Ren W, Hu DS, Shi Y, et al. Immunoglobulin alpha heavy chain derived from human epithelial cancer cells promotes the access of $S$ phase and growth of cancer cells. Cell Biol Int. 2007;31:82-87.

75. Li M, Zheng H, Duan Z, Liu H, Hu D, Bode A, et al. Promotion of cell proliferation and inhibition of ADCC by cancerous immunoglobulin expressed in cancer cell lines. Cell Mol Immunol. 2012;9:54-61.

76. Wang J, Lin D, Peng H, Shao J, Gu J. Cancer-derived immunoglobulin G promotes LPS-induced proinflammatory cytokine production via binding to TLR4 in cervical cancer cells. Oncotarget. 2014:5:9727-43.

77. Liao Q, Liu W, Liu Y, Wang F, Wang C, Zhang J, et al. Aberrant high expression of immunoglobulin $\mathrm{G}$ in epithelial stem/progenitor-like cells contributes to tumor initiation and metastasis. Oncotarget. 2015;6:40081-94.

78. Lee G, Ge B. Inhibition of in vitro tumor cell growth by RP215 monoclonal antibody and antibodies raised against its anti-idiotype antibodies. Cancer Immunol Immunother. 2010;59:1347-56.

79. Lee G. Cancerous immunoglobulins and CA215: implications in cancer immunology. Am J Immunol. 2012;8:101-16.

80. Lee G, Huang CY, Liu SF, Chien CH, Chow SN. Dual roles of cancer cell-expressed immunoglobulins in cancer immunology. Am J Immunol. 2014;10:156-65.

81. Lee G, Cheung AP, Ge B, Zhu M, Giolma B, Li B, et al. CA215 and GnRH receptor as targets for cancer therapy. Cancer Immunol Immunother. 2012;61:1805-17.

82. Lee G, Liu S, Huang C. Human serum proteins recognized by CA215 and cancerous immunoglobulins and implications in cancer immunology. Cancer Clin Oncol. 2014;3:51-69.

83. Xu $Y$, Chen $B$, Zheng $S$, Wen $Y, X u A$, Xu K, et al. IgG silencing induces apoptosis and suppresses proliferation, migration and invasion in LNCaP prostate cancer cells. Cell Mol Biol Lett. 2016;3:21-27.
84. Chu J, Li Y, Deng Z, Zhang Z, Xie Q, Zhang H, et al. IGHG1 regulates prostate cancer growth via the MEK/ERK/c-Myc pathway. Biomed Res Int. 2019;2019:7201562.

85. Liu Y, Liu D, Wang C, Liao Q, Huang J, Jiang D, et al. Binding of the monoclonal antibody RP215 to immunoglobulin G in metastatic lung adenocarcinomas is correlated with poor prognosis. Histopathology. 2015;67:645-53.

86. Liu EY, Liu JF, Shao WW, Xiao L, Li GH, Chang XH, et al. Tumor derived IgG suppress the proliferation of T cells in cord blood. Beijing Da Xue Xue Bao Yi Xue Ban. 2017;49:824-8.

87. Wang Z, Geng Z, Shao W, Liu E, Zhang J, Tang J, et al. Cancer-derived sialylated IgG promotes tumor immune escape by binding to Siglecs on effector T cells. Cell Mol Immunol. 2020;17:1148-62.

88. Miao S, Shu D, Zhu Y, Lu M, Zhang Q, Pei Y, et al. Cancer cell-derived immunoglobulin $\mathrm{G}$ activates platelets by binding to platelet FcyRlla. Cell Death Dis. 2019;10:87.

89. Wang JP, Chen HY, Peng H. Functional analysis of cancer-derived immunoglobulin $\mathrm{G}$ whole molecule-interacting proteins identified by LC-MS/MS. Nan Fang. Yi Ke Da Xue Xue Bao. 2015;35:93-97.

90. Tonegawa S. Reiteration frequency of immunoglobulin light chain genes: further evidence for somatic generation of antibody diversity. Proc Natl Acad Sci USA. 1976;73:203-7.

91. Lieber M. Immunoglobulin diversity: rearranging by cutting and repairing. Curr Biol. 1996;6:134-136

92. Lambin P. Immunoglobulin genes and the origin of antibody diversity. Rev $\mathrm{Fr}$ Transfus Hemobiol. 1992;35:47-65.

93. Feige MJ, Hendershot LM, Buchner J. How antibodies fold. Trends Biochem Sci. 2010;35:189-198.

94. Deisenhofer J. Crystallographic refinement and atomic models of a human Fc fragment and its complex with fragment B of protein A from Staphylococcus aureus at 2.9- and 2.8-A resolution. Biochemistry. 1981;20:2361-70.

95. Mizuochi T, Taniguchi T, Shimizu A, Kobata A. Structural and numerical variations of the carbohydrate moiety of immunoglobulin G. J Immunol. 1982;129:2016-20.

96. Gudelj I, Lauc G, Pezer M. Immunoglobulin G glycosylation in aging and diseases. Cell Immunol. 2018;333:65-79.

97. Lee Gregory, Azadi, Peptide Parastoo. mapping and glycoanalysis of cancer cellexpressed glycoproteinsCA215 recognized by RP215 monoclonal antibody. J Carbohydr Chem. 2012;31:10-30.

98. Lee $\mathrm{G}$, Laflamme $\mathrm{E}$, Chien $\mathrm{CH}$, Ting $\mathrm{HH}$. Molecular identity of a pan cancer marker, CA215. Cancer Biol Ther. 2008;7:2007-14.

99. Lee G, Huang CY, Liu SF, Zhang H. The immunology of cancer cells. SOJ Immunol. 2013;1:4.

100. Chen Z, Qiu X, Gu J. Immunoglobulin expression in non-lymphoid lineage and neoplastic cells. Am J Pathol. 2009;174:1139-48.

101. Huang J, Sun X, Gong X, He Z, Chen L, Qiu X, et al. Rearrangement and expression of the immunoglobulin $\mu$-chain gene in human myeloid cells. Cell Mol Immunol. 2014;11:94-104.

102. Wen L, Yang S, Zhu P, Yu Y, Qiu X, Fu N, et al. Peptide mimics of a carbohydrateassociated epitope expressed by cancer cells: Identification of vaccine candidates. Mol Med Rep. 2016;14:5237-44.

\section{AUTHOR CONTRIBUTIONS}

JW conceived the ideas. JW wrote the manuscript and designed figures and tables together with JZ, HP, JG, AN, HH, SY, LC, XW, and HZ. All authors read and approved the final manuscript.

\section{FUNDING}

This work was supported by grants of the National Natural Science Foundation of China (81760513 and 82060528), the Guangxi Natural Science Foundation of China (2017JJA10351 and 2019JJA140532), the Basic Ability Promotion Project for Young and Middle-Aged College Teachers in Guangxi Zhuang Autonomous Region (2017KY0520), the Scientific Research Project of Youjiang Medical University for Nationalities (yy2016bsky02), the Scientific Research Open Project of Key Laboratory in Guangxi's Universities (kfkt2017005), the Innovation Project of Guangxi Graduate Education (YCSW2020232 and YCSW2021342), the Guangxi Undergraduate Innovation and Entrepreneurship Training Program (201810599043, 201810599036, 202010599011, and 202010599025).

\section{ETHICS STATEMENT}

Not applicable. 
12

\section{COMPETING INTERESTS}

The authors declare no competing interests.

\section{ADDITIONAL INFORMATION}

Correspondence and requests for materials should be addressed to J.W.

Reprints and permission information is available at http://www.nature.com/ reprints

Publisher's note Springer Nature remains neutral with regard to jurisdictional claims in published maps and institutional affiliations.
Open Access This article is licensed under a Creative Commons Attribution 4.0 International License, which permits use, sharing, adaptation, distribution and reproduction in any medium or format, as long as you give appropriate credit to the original author(s) and the source, provide a link to the Creative Commons license, and indicate if changes were made. The images or other third party material in this article are included in the article's Creative Commons license, unless indicated otherwise in a credit line to the material. If material is not included in the article's Creative Commons license and your intended use is not permitted by statutory regulation or exceeds the permitted use, you will need to obtain permission directly from the copyright holder. To view a copy of this license, visit http://creativecommons.org/licenses/by/4.0/.

(c) The Author(s) 2021 